\title{
Voltage Control of Dual Active Bridge Converter for CO-Amorphous Core Material Based Solid- State Transformer Application
}

\author{
Kalpana Meena ${ }^{1}$, D. K. Palwalia ${ }^{2}$ \\ M.Tech Scholar, Department of Electrical Engineering, Rajasthan Technical University, Kota, India ${ }^{1}$ \\ Professor, Department of Electrical Engineering, Rajasthan Technical University, Kota, India ${ }^{2}$
}

\begin{abstract}
Solid-State Transformer (SST) provides versatile power system operation. In the smart world, there are technologies where everything is incorporated that reduce the size and eventually save time in delivering a fast process. It has been seen that solid-state transformer voltage begins to decrease during operation that needs to be regulated through some control strategy. In this paper, a Dual Active Bridge (DAB) converter has been used to control the voltage of SST that employs the Single-Phase Shift (SPS) technique. For further efficiency improvement $\mathrm{Co}_{73}\left(\mathrm{Si}_{1}, \mathrm{~B}\right)_{27}$ co-amorphous material has been used for the core of SST because co-amorphous alloy has much lower loss compared with Fe-amorphous cores and have limited saturation flux density. Real-time parameters of core have been used in the analysis. It has been evident from the results that DAB dc-dc converter-based SST with SPS control technique is simple and offers better performance compared to stand-alone SST. It improves the overall performance and efficiency of the system. This paper has been accomplished in Matlab ${ }^{\circledR} /$ Simulink environment.
\end{abstract}

Keywords: $\mathrm{Co}_{73}(\mathrm{Si}, \mathrm{B})_{27}$ Amorphous Core Material; Solid-State transformer (SST); Dual Active Bridge (DAB); High voltage (HV) Application.

\section{INTRODUCTION}

Here in the modern world, with the population, power demand is rising. Most of the energy is consumed for industrial purposes. Industrial load and basic commercial operations are suffering from interference in supply which results in loss of generation. In summer days, power losses increase manifolds as copper gets heated up with time. This also results in increased copper losses. Conventional transformers have poor regulation of power, low efficiency, and output load can be interrupted by the interference of input sources such as the presence of harmonics, reactive power components, and throwback of transient behaviour at the input side [1]. To overcome these issues a special kind of transformer has been developed that is superior and compelling to a conventional transformer named solid-state transformer (SST) which is based on the semiconductor material [2]. As compared to conventional transformer SST has advantages such as less weight, high frequency, high power with high voltage, and both reactive and active power control and it also provides protection against voltage sag and swells and reduces losses. In SST there are semiconductor devices that are used [3][4]. The purpose of semiconductor devices is to generate a voltage at a medium frequency (several $\mathrm{kHz}$ to tens of $\mathrm{kHz}$ ) that is step-up/down by Structure medium frequency transformer and again this voltage is converted into low-frequency voltage. Semiconductor devices, gate drivers, inductors, capacitors, and control systems are needed in the development of SST. SST has different configurations, among which the most advantageous configuration is AC-DC-DC-AC conversion which provides power factor correction, active- reactive power compensation, and also provides DC output. It also incorporates some additional features [5-7]. It supports reactive power grid, storage management, and provide DC output. It has been also interfaced with photovoltaic (PV) generation, plug-in hybrid electric vehicles (PHEV), storage systems like batteries, and electric loads. SST is isolated with high power converters having their applications within the renewable energy system such as solar and wind energy sources [8-11]. A DAB dual bridge converter for solid-state transformer which is a bidirectional dc-dc converter using a highfrequency transformer to step down or step up the voltage at high frequency to reduce the size of the transformer while at the same time maintaining the system efficiency and reliability [12-15]. This converter is controlled by phase shift modulation. 
International Journal of Innovative Research in Electrical, Electronics, Instrumentation and Control Engineering

Vol. 8, Issue 10, October 2020

DOI 10.17148/IJIREEICE.2020.81007

\section{Dual ACTIVE BRIDGe (DAB) Configuration}

SST has the capability of bidirectional power flow; its internal dc bus provides to link with renewable energy sources and dc load [10]. It interfaces between medium voltage grid and residential voltage utility ports. The flow of power can be controlled and it distributed along with the low voltage buses and power flow back into the grid. This increases a highly distributed network of electricity. Input AC power from the supply is feed into AC/DC converter their AC converted into DC. This DC is going into DC/AC converter it is the primary $\mathrm{H}$ - bridge of dual active bridge (DAB). In primary H-bridge this DC convert into AC which feeds into a small high-frequency transformer which is isolated with DAB [4]. Another side of DAB is the secondary H-bridge which converts AC into DC where we can get DC output or can change into AC.

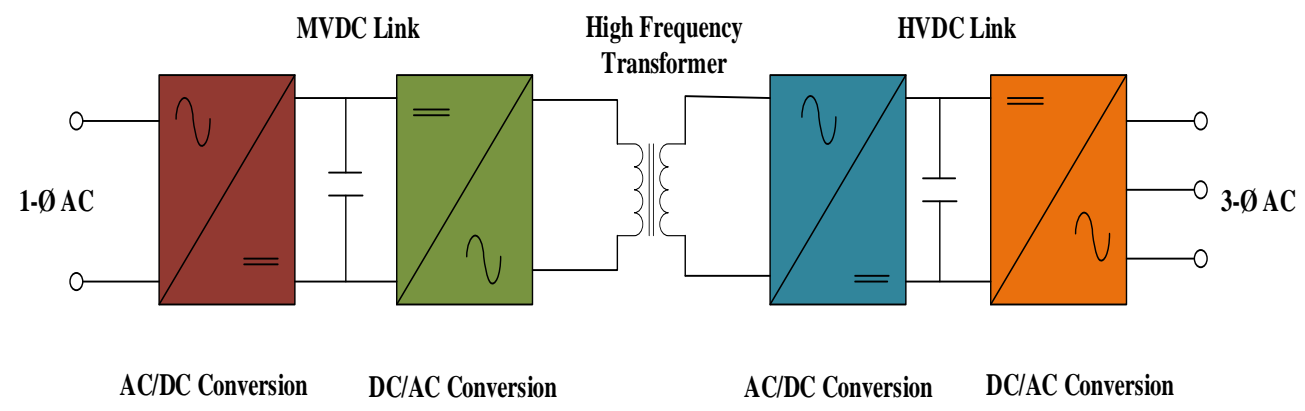

Fig.1 Schematic diagram of solid state transformer

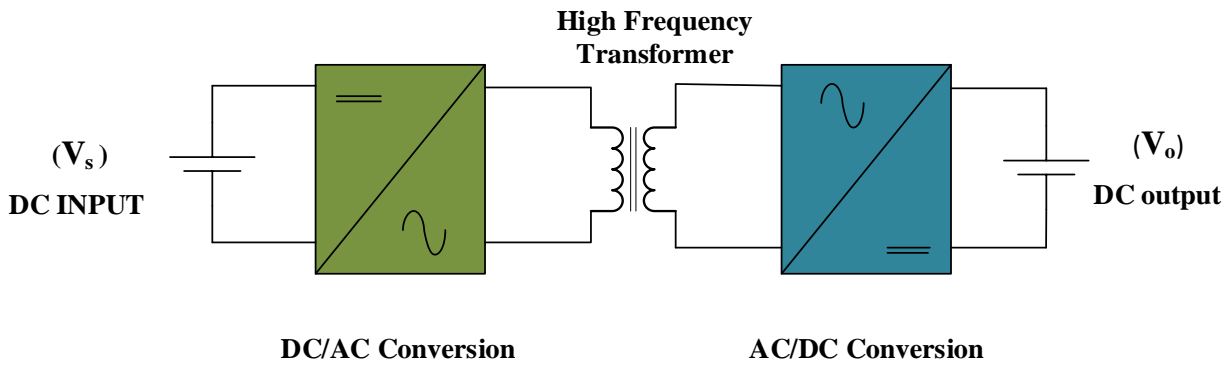

Fig. 2 Dual active bridge

This system provides regulated power and power factor improvement. The schematic diagram of the solid-state transformer is shown in figure 1. The cost of the system will increase during the increased current stress and performance decreases that may affect the system. DAB can flow of power in both directions. The dual active bridge is shown in figure 2.

A. Working of $D A B$

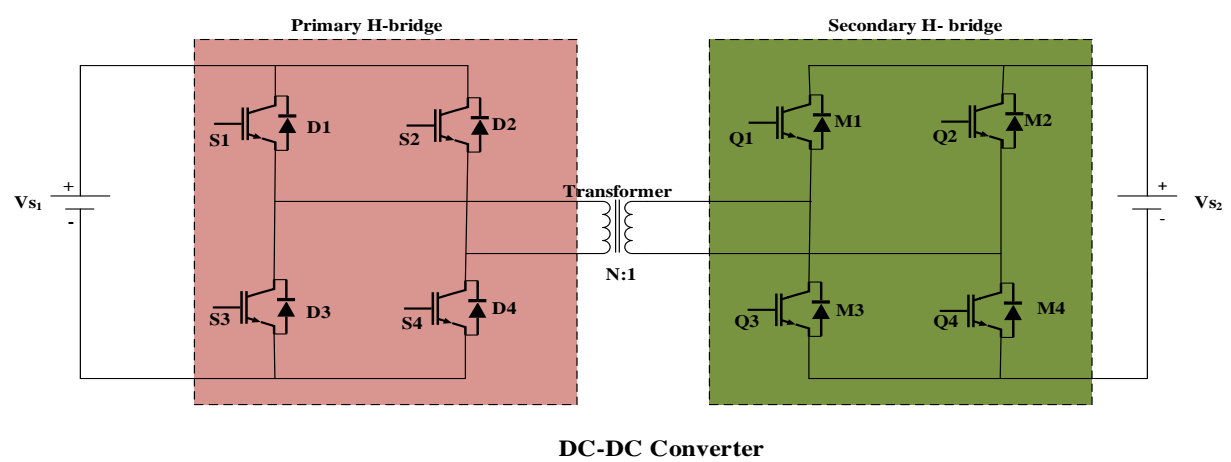

Fig. 3 Configuration circuit of isolated bidirectional dual active bridge 
International Journal of Innovative Research in

Electrical, Electronics, Instrumentation and Control Engineering

Vol. 8, Issue 10, October 2020

DOI 10.17148/IJIREEICE.2020.81007

There are two converters in the dual active bridge that access high-frequency transformers for galvanic insulation. SST needs bidirectional switches for power flow. Bidirectional power flow is offered by the DAB. For soft switching, a condenser is used parallel to the $\mathrm{H}$-bridge. DAB is operating at constant rated power. A 1-phase H-bridge DAB DC-DC converter has shown in figure 3. Each H-bridge features two legs. There are four switches with four anti-parallel diodes on the low voltage (LV) side. Through the switches S1, S2 \& S3, S4, diodes D1, D2 \& D3, D4 are connected in antiparallel mode. Similarly, via the switches Q1, Q2 \& Q3, Q4, diodes M1, M2 \& M3, M4 are connected in anti-parallel. Between Two H- Bridges, a high-frequency transformer is linked. Via the key H- Bridge, input signal VS1 is applied. Switches S1 \& S2 are turn-on at time t1 and Q1 \& Q4 are switched on after 50 percent delay switches. At the same time, the S2 \& S3 t2 switches are ON. Switches Q2 \& Q3 are ON after delivering the step shift.

The power flow equation for SPS control technique is expressed as

$$
\mathrm{P}=V_{o} N \frac{V_{s} D(1-D)}{2 * f_{s} * L}
$$

Where, $\mathrm{Vs}=$ Primary side voltage, $\mathrm{V}_{0}=$ Secondary side voltage, $\mathrm{N}=$ Transformation Ratio, $\mathrm{D}=$ Phase shifting ratio, $f_{S}$ $=$ Switching frequency, $\mathrm{L}=$ inductance

\section{III.MATERIAL USED IN TRANSFORMER}

Various magnetic materials are used in high power applications such as- silicon steel, ferrite, amorphous, and nanocrystalline. Compared with Fe-amorphous cores, the co-amorphous alloy has a much lower loss and reduced saturation flux density [1]. Silicon steel cores have high saturation flux density with having high permeability. Losses are high in silicon steel cores with high-frequency applications. In ferrite material core the losses are moderate and the cost of material is low and low saturation flux density. This type of material the size of the core is large that's why it is not applicable for SST. The nanocrystalline core is the best among all with having high power density and efficiency. The losses are too low in nanocrystalline material but the cost of this material is high. The amorphous alloy has high flux density and losses are moderate. The cost of material is lower than the nanocrystalline core material. It is also suitable for high power applications.

Table 1. Comparison between different magnetic materials

\begin{tabular}{|c|c|c|l|l|l|}
\hline Material & $\begin{array}{c}\text { Alloy } \\
\text { composition }\end{array}$ & $\begin{array}{l}\text { Loss(W/kg) } \\
(\mathbf{2 0 K H z , 0 . 2 T})\end{array}$ & $\begin{array}{c}\text { Saturation } \\
\mathbf{B}_{\text {sat }}(\mathbf{m T})\end{array}$ & $\begin{array}{c}\text { Permeability } \\
\mathbf{( 5 0 H z}) \\
\boldsymbol{\mu}_{4}-\boldsymbol{\mu}_{\text {max }}\end{array}$ & $\begin{array}{c}\text { Max. working } \\
\text { Temp. }\left({ }^{\circ} \mathbf{C}\right)\end{array}$ \\
\hline Grain-oriented silicon steel & $\mathrm{Fe}_{97} \mathrm{Si}_{3}$ & $>1000$ & 2000 & $2 \mathrm{~K}-35 \mathrm{~K}$ & 120 \\
\hline Advanced silicon steel & $\mathrm{Fe}_{93.5} \mathrm{Si}_{6.5}$ & 40 & 1300 & $16 \mathrm{~K}$ & 130 \\
\hline High-performance ferrite & $\mathrm{M}_{\mathrm{n}} \mathrm{Z}_{\mathrm{n}}$ & 17 & 500 & $1.5 \mathrm{~K}-15 \mathrm{~K}$ & $100 / 120$ \\
\hline Fe-amorphous alloy & $\mathrm{Fe}_{76}(\mathrm{Si}, \mathrm{B})_{24}$ & 18 & 1560 & $6.5 \mathrm{~K}-8 \mathrm{~K}$ & 150 \\
\hline Co-amorphous alloy a & $\mathrm{Co}_{73}(\mathrm{Si}, \mathrm{B})_{27}$ & 5 & 550 & $100 \mathrm{~K}-150 \mathrm{~K}$ & $90 / 120$ \\
\hline Co-amorphous alloy b & $\mathrm{Co}_{77}(\mathrm{Si}, \mathrm{B})_{23}$ & 5.5 & 820 & $2 \mathrm{~K}-4.5 \mathrm{~K}$ & 120 \\
\hline Co-amorphous alloy c & $\mathrm{Co}_{80}(\mathrm{Si}, \mathrm{B})_{20}$ & 6.5 & 1000 & $1 \mathrm{~K}-2.5 \mathrm{~K}$ & 120 \\
& & & & & \\
\hline
\end{tabular}

\section{IV.SPS CONTROL TECHNIQUE}

Single-phase shift (SPS) is a very common dual active bridge control scheme. The SPS phase shift preserves the direction of voltage and power flow on both sides of the high-frequency transformer [5]. Because of the high circulating current, when the voltage amplitude of both the SST side is unbalanced, there is an increase in the resulting 
International Journal of Innovative Research in Electrical, Electronics, Instrumentation and Control Engineering

Vol. 8, Issue 10, October 2020

\section{DOI 10.17148/IJIREEICE.2020.81007}

RMS and maximum current that increases the power losses and reduces its efficiency [16-20]. By using the SPS control strategy, these issues are eliminated. Figure 4, shows the primary and secondary gate pulse structures.
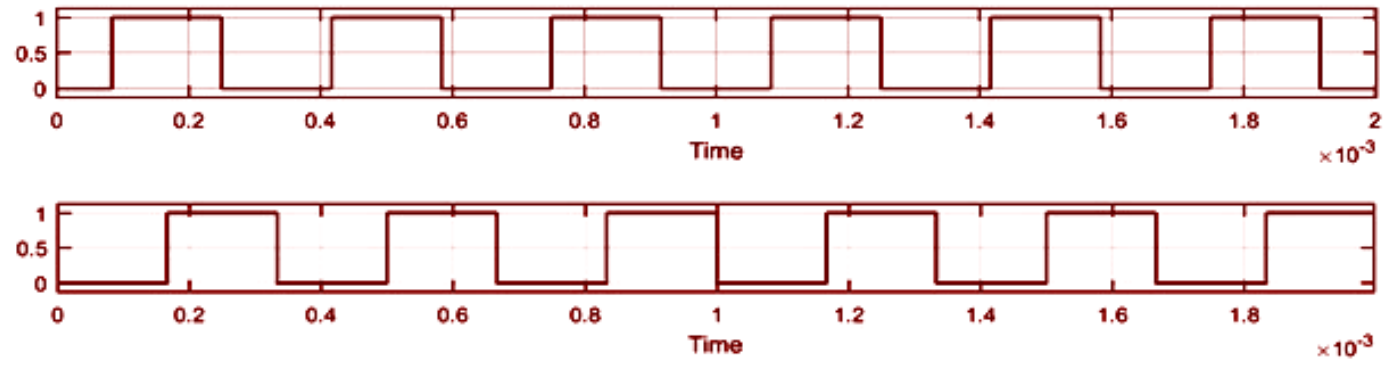

Fig.4 Primary gate pulse and secondary gate pulse

A. Design of control system for Single-phase shift technique

A dual active bridge DC-DC converter closed-loop control system has been used in which the secondary H-Bridge output voltage $\left(\mathrm{V}_{\mathrm{O}}\right)$ is compared with the reference voltage value $\left(\mathrm{V}_{\text {ref }}\right)$. Also, it feeds this error signal into the PI controller. This signal compares with the secondary H-bridge output current $\left(\mathrm{I}_{0}\right)$ and creates an error signal for this error, which is further transmitted to the PI controller [18]. The PI controller provides phase shifting between pulses. A schematic diagram of the SPS dual active bridge DC-DC converter control system, shown in Fig.5.

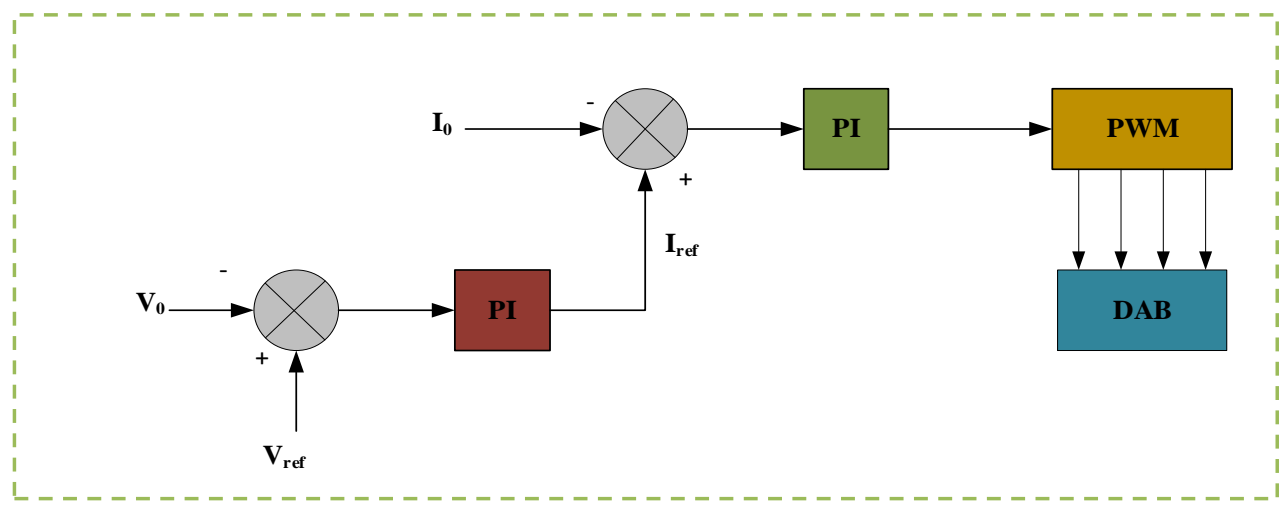

Fig.5 Control system design for SPS Control Technique

\section{RESUlt \& DISCUSSION}

The Proposed DC-DC DAB has been simulated in MATLAB ${ }^{\circledR}$ Simulink environment. Figure 6(a) presents the primary side of SST voltage that is $3800 \mathrm{~V}$ AC, the primary side voltage is not pure sinusoidal and the voltage goes to zero. From Figure 6(b) it is evident that the voltage is stepped down to $400 \mathrm{~V} \mathrm{AC}$ at the secondary side but it is also not a pure sine wave and the voltage goes to dip at a certain time interval and voltage becomes zero at time $0.2 \mathrm{sec}$, that makes the system unstable. As the DC-link capacitor is connected, ripples have been seen in output DC. 


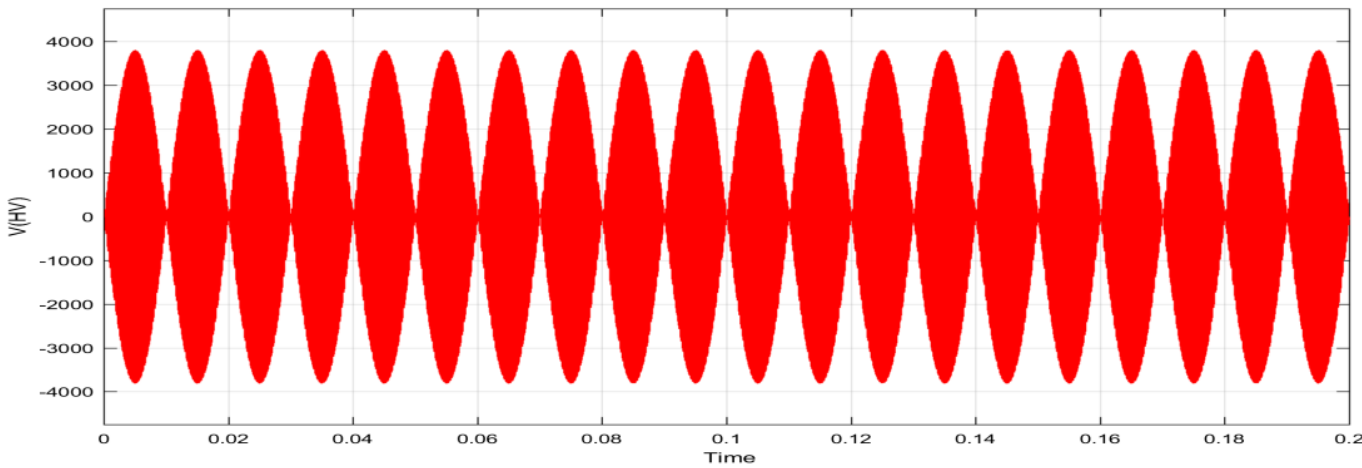

(a)

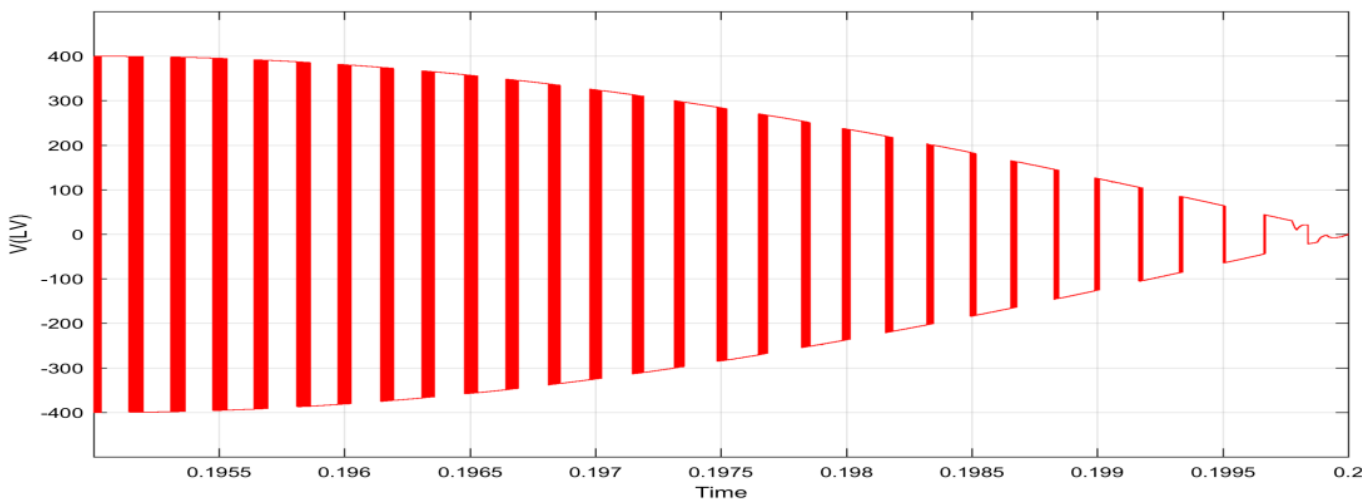

(b)

It is due to the unbalancing of the dual active bridge. Figure 6(c) shows the output voltage of SST without SPS control. So it is necessary to apply a control strategy in the system to balance the output voltage. Further figure 7(a) shows the output voltage of the primary H-Bridge. The input voltage of the primary side is $3800 \mathrm{~V}$ DC and the output voltage of the H-Bridge is a square wave. The SPS control technique is used here which improves the voltage of the system and stability. Further figure 7(b) presents the secondary voltage of SST. It is a low voltage side of SST. The low voltage is $400 \mathrm{~V}$ AC. It shows that during the time interval 0 to $0.02 \mathrm{sec}$ the voltage is increased from 0 to $400 \mathrm{~V}$. After a time interval of $0.02 \mathrm{sec}$, the voltage is stable and provides AC square waves. Figure $7(\mathrm{c})$ shows the output voltage of the secondary $\mathrm{H}-\mathrm{Bridge}$ that is $400 \mathrm{~V} \mathrm{DC}$.

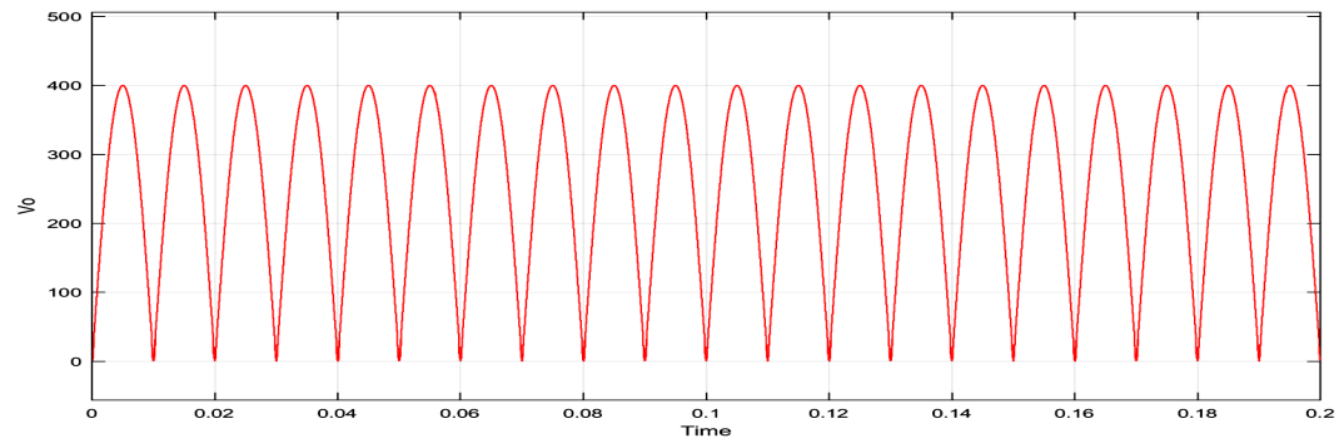

(c)

Fig.6 Simulation result of SST without using SPS control. (a) Voltage at primary H-Bridge of SST at high voltage side. (b) Voltage at secondary H- Bridge of SST at low voltage side. (c) Output voltage of SST. 
International Journal of Innovative Research in Electrical, Electronics, Instrumentation and Control Engineering

Vol. 8, Issue 10, October 2020

DOI 10.17148/IJIREEICE.2020.81007

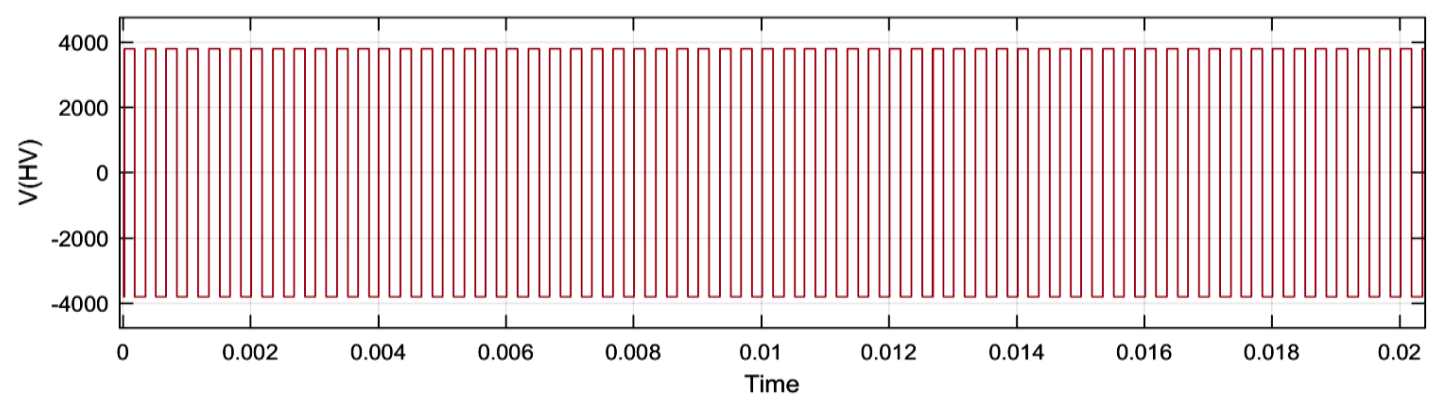

(a)

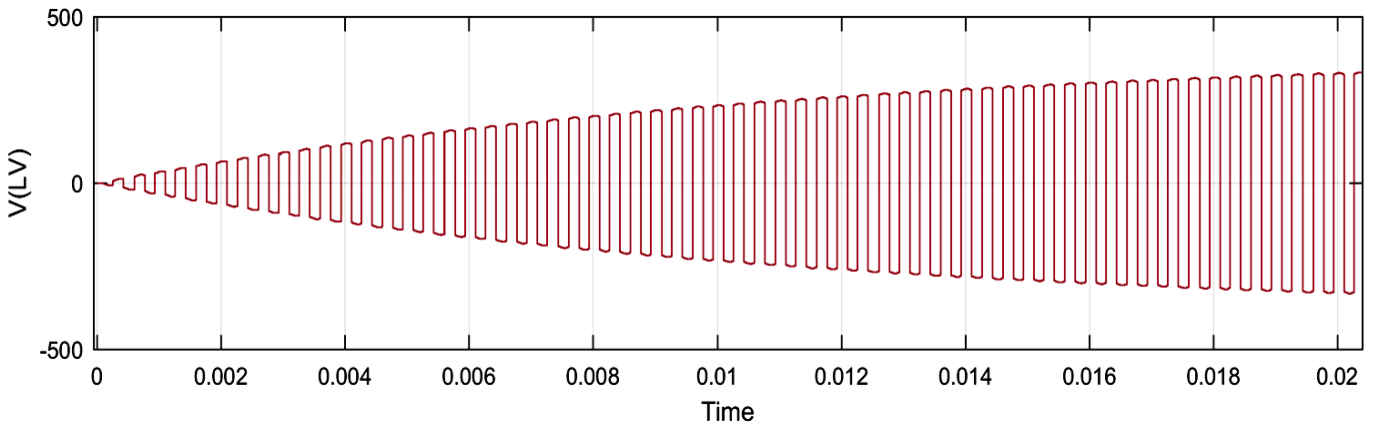

(h)

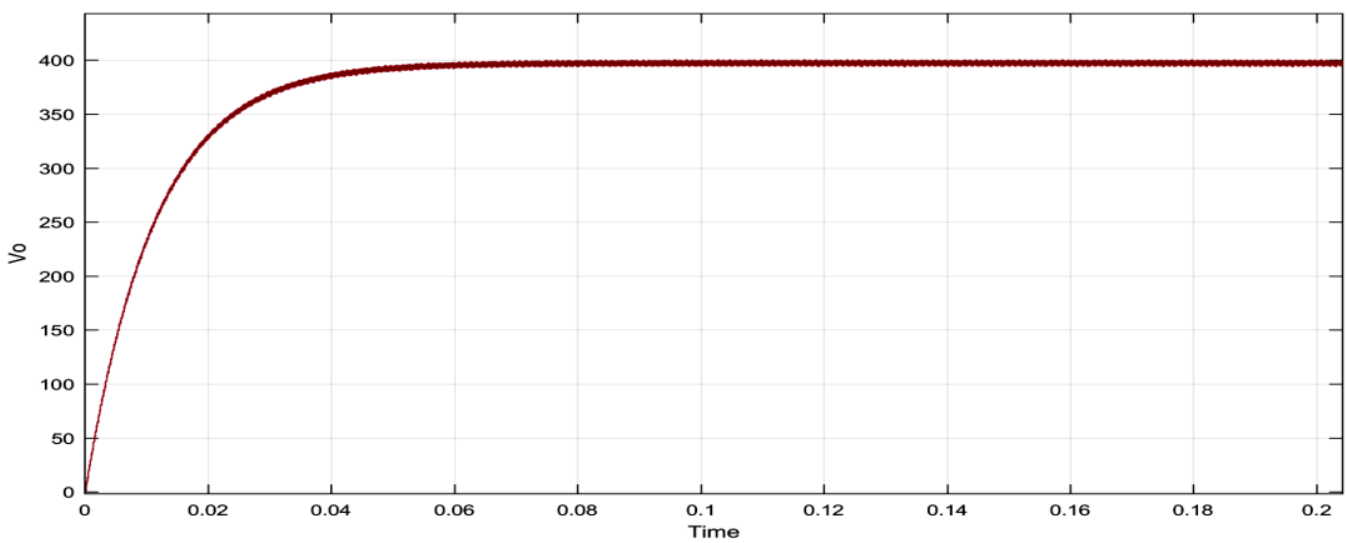

(c)

Fig.7 Simulated result of SST with using SPS control (a) Voltage at primary H-Bridge of SST at high voltage side. (b) Voltage at secondary H- Bridge of SST at low voltage side. (c) Output voltage of SST.

\section{VI.CONCLUSION}

As the $\mathrm{CO}_{73}(\mathrm{Si}, \mathrm{B})_{27}$ co-amorphous material has much lower loss compared with $\mathrm{Fe}$-amorphous cores and have limited saturation flux density, it has been used for the core of SST. The isolated dual active bridge DC-DC converter with a single-phase shift control technique is exhibited via simulated results in MATLAB. This system offers the balancing of the voltage from both sides of the dual active bridge as well as improving the performance of the system and stability of the system. The SPS control based DAB converter plays an important role, offering reliable performance. This technique of close loop control also helps the system to maintain the necessary voltage on both sides of the Coamorphous core material based SST. The strategy of SPS control with the PI controller enhances its steady-state 
International Journal of Innovative Research in

Electrical, Electronics, Instrumentation and Control Engineering

Vol. 8, Issue 10, October 2020

\section{DOI 10.17148/IJIREEICE.2020.81007}

efficiency. In comparison to stand-alone SST, it is also evident that DAB dc-dc converter-based SST with SPS control technique is simple and offers superior results in terms of high system stability.

\section{REFERENCES}

[1] X. She, A. Q. Huang and R. Burgos, "Review of Solid-State Transformer Technologies and Their Application in Power Distribution Systems," in IEEE Journal of Emerging and Selected Topics in Power Electronics, vol. 1, no. 3, pp. 186-198, Sept. 2013, doi: 10.1109/JESTPE.2013.2277917.

[2] H. Fan and H. Li, "High-frequency transformer isolated bidirectional DC-DC converter modules with high efficiency over wide load range for 20 kVA solid-state transformer," IEEE Trans. Power Electron., vol. 26, no. 12, pp. 3599-3608, 2011, doi: 10.1109/TPEL.2011.2160652.

[3] B. Zhao, Q. Song, W. Liu, and Y. Sun, "Overview of dual-active-bridge isolated bidirectional DC-DC converter for high-frequency-link power-conversion system," IEEE Trans. Power Electron., vol. 29, no. 8, pp. 4091-4106, 2014, doi: 10.1109/TPEL.2013.2289913.

[4] K. Meena, K. Jayaswal and D. K. Palwalia, "Analysis of Dual Active Bridge Converter for Solid State Transformer Application using Single-Phase Shift Control Technique," 2020 International Conference on Inventive Computation Technologies (ICICT), Coimbatore, India, 2020, pp. 1-6, doi: 10.1109/ICICT48043.2020.9112398.

[5] B. M. Kumar, A. Kumar, A. H. Bhat, and P. Agarwal, "Comparative study of dual active bridge isolated DC to DC converter with single phase shift and dual phase shift control techniques," 2017 Recent Dev. Control. Autom. Power Eng. RDCAPE 2017, vol. 3, pp. 453-458, 2018, doi: 10.1109/RDCAPE.2017.8358314.

[6] Svalov, A.V., Kudyukov, E.V., Balymov, K.G. et al., "Thickness Dependence of Magnetic Properties of $\mathrm{Tb}-\mathrm{Co} / \mathrm{Ti}$ and $\mathrm{Tb}-\mathrm{Co} / \mathrm{Si}$ Multilayers" Phys. Metals Metallogr, vol. 120, pp. 1260-1265, 2019, https://doi.org/10.1134/S0031918X19130258

[7] A. Tong, L. Hang, G. Li, and J. Xu, "Equivalent circuit model of dual active bridge converter," Proc. IECON 2017 - $43 r d$ Annu. Conf. IEEE Ind. Electron. Soc., vol. 2017-Janua, pp. 4677-4682, 2017, doi: 10.1109/IECON.2017.8216806.

[8] G. Kapoor, N. Gautam, K. jayaswal and S. Tripathi, "Protection of Series Capacitor Compensated Double Circuit Transmission Line Using Wavelet Transform," 2019 IEEE 5th International Conference for Convergence in Technology (I2CT), Bombay, India, 2019, pp. 1-8, doi: 10.1109/12CT45611.2019.9033583

[9] H. Qin and J. W. Kimball, “Ac-Ac dual active bridge converter for solid state transformer," 2009 IEEE Energy Convers. Congr. Expo. ECCE 2009, pp. 3039-3044, 2009, doi: 10.1109/ECCE.2009.5316507.

[10] G. Kapoor, S. Tripathi, G. Jain and K. jayaswal, "Detection of Fault and Identification of Faulty Phase in Series Capacitor Compensated Transmission Line Using Wavelet Transform," 2019 IEEE 5th International Conference for Convergence in Technology (I2CT), Bombay, India, 2019, pp. 1-8, doi: 10.1109/12CT45611.2019.9033807.

[11] J. W. Van Der Merwe and H. Du, "The solid-state transformer concept: A new era in power distribution," IEEE AFRICON Conf., pp. 1-6, 2009, doi: 10.1109/AFRCON.2009.5308264.

[12] Kuldeep jayaswal, DK Palwalia, "Performance Analysis of Non-Isolated DC-DC Buck Converter Using Resonant Approach", Engineering, Technology \& Applied Science Research, vol. 8, No. 5, pp. 3350-3354, October 2018.

[13] S. Bhattacharya et al., "Design and development of generation-I silicon based solid state transformer," Conf. Proc. - IEEE Appl. Power Electron. Conf. Expo. - APEC, pp. 1666-1673, 2010, doi: 10.1109/APEC.2010.5433455.

[14] Kuldeep jayaswal, Dheeraj kumar palwalia, Gaurav jain, Prakash kumar, "Design-Oriented Analysis of Non-isolated DC-DC Buck Converter", Ciencia e Tecnica Vitivinicola journal, vol. 30, no. 2, pp. 177-213, February 2015.

[15] H. Qin and J. W. Kimball, "Solid-state transformer architecture using AC-AC dual-active-bridge converter," IEEE Trans. Ind. Electron., vol. 60, no. 9, pp. 3720-3730, 2013, doi: 10.1109/TIE.2012.2204710.

[16] Jayaswal, K., Palwalia, D.K. \& Kumar, S. Analysis of robust control method for the flexible manipulator in reliable operation of medical robots during COVID-19 pandemic. Microsyst Technol (2020). https://doi.org/10.1007/s00542-020-05028-9

[17] H. Chen and D. Divan, "Soft-Switching Solid-State Transformer (S4T)," IEEE Trans. Power Electron., vol. 33, no. 4, pp. 2933-2947, 2018, doi: 10.1109/TPEL.2017.2707581.

[18] N. Gupta, S. P. Singh, S. P. Dubey, and D. K. Palwalia, "Digital Signal Processor based Performance Investigation of Indirect Current Controlled Active Power Filter for Power Quality Improvement," Int. J. Emerg. Electr. Power Syst., vol. 13, no. 2, 2012.

[19] D. K. Palwalia, "DSP-based fuzzy load controller for single-phase self-excited induction generator," Int. J. Power Electron., vol. 3, no. 5, pp. 453-468, 2011

[20] D. K. Palwalia and S. P. Singh, "Design and implementation of induction generator controller for single-phase self-excited induction generator," 2008 3rd IEEE Conf. Ind. Electron. Appl. ICIEA 2008, pp. 400-404, 2008. 